\title{
CHANGE OF BREAST HEIGHT DIAMETER WITH AGE OF Swietenia macrophylla (MAHOGANY) EVEN-AGED MONOCULTURES
}

\author{
W.A.S. Lakmali and S.M.C.U.P.Subasinghe \\ Department of Forestry and Environmental Science, University of Sri Jayewardenepura, \\ Sri Lanka. \\ E-mail-shyanika_lakmali@yahoo.com, Tel-+ 94716319251
}

\begin{abstract}
Growth models are important tools for growth and yield prediction in forest plantations. Species specific growth models facilitate to investigate appropriate management guidelines and silvicultural strategies. Mahogany is one of the imperative timber species in commercial plantation sector in Sri Lanka. Most of the mahogany plantations are managed in order to receive a higher financial return while maintaining of shorter rotations. However, growth models in such aspects are lacking in Sri Lanka for the above aspects. Therefore this study is important, as it investigated the distribution of breast height diameter (dbh) of mahogany trees growing in different site types with their age.

For this study, data were collected from sixteen mahogany monocultures in Kalutara, Ratnapura and Matale districts. In order to represent growth of the whole plantation, each plantation was visually categorized in to good, moderate and poor sites. Twenty trees were selected from each site and altogether sixty trees were selected from each plantation. A theoretical basic model structure was developed between dbh and age for each site types, in order to establish a model to find out the relationship between dbh and age of mahogany. That basic structure was tested with linear regression analysis and non-linear regression analysis such as exponential and logistic functions. In addition to the untransformed explanatory variables, several transformations were also used for identification of the best model. The best equation was selected using $\mathrm{R}^{2}$ value and analyzing residual distribution. Further, a common model was tested for all site types with pooled data as it is difficult to use different models for different site types. However, further analysis proved that this attempt was not successful. Therefore it was decided to build growth specific models to express relationship between dbh and age of mahogany.
\end{abstract}

For the three finally selected models for three site types (good, moderate and poor), dbh has an exponential relationship with height. The $\mathrm{R}^{2}$ values were above $70 \%$ and the residual distributions were good. Finally, a height based site/growth classification system was also introduced in this study, so that the appropriate model can be used for the selected site type.

Key words: Mahogany, Growth models, Yield prediction

\section{INTRODUCTION}

Swietenia macrophylla (mahogany) is native to North America and now it covers a wide range of terrestrial areas in the world including tropical countries. The suitability of mahogany as a plantation crop has led to established 200,000 ha of plantations worldwide, with extensive areas in Fiji and Philippines (Platino, 1997). In Sri Lanka, private sector also started to establish mahogany monocultures specially in the intermediate zone and low country wet zone.

Information on growth of mahogany is not readily available in Sri Lanka. As a solution for this, it is necessary to establish appropriate management guidelines for mahogany monoculture plantations. Prior to introduce such management strategies, it is further necessary to identify the growth rates and growth differences of mahogany as a plantation crop. In order to address this requirement, the present study was conducted to identify the distribution of breast height diameter (dbh) of mahogany trees growing in different site types with their age.

Proceedings of the $15^{\text {th }}$ International Forestry and Environment Symposium, 26-27 November 2010.

Published by Department of Forestry and Environmental Science, University of Sri Jayewardenepura, Sri Lanka. 


\section{MATERIALS AND METHODS}

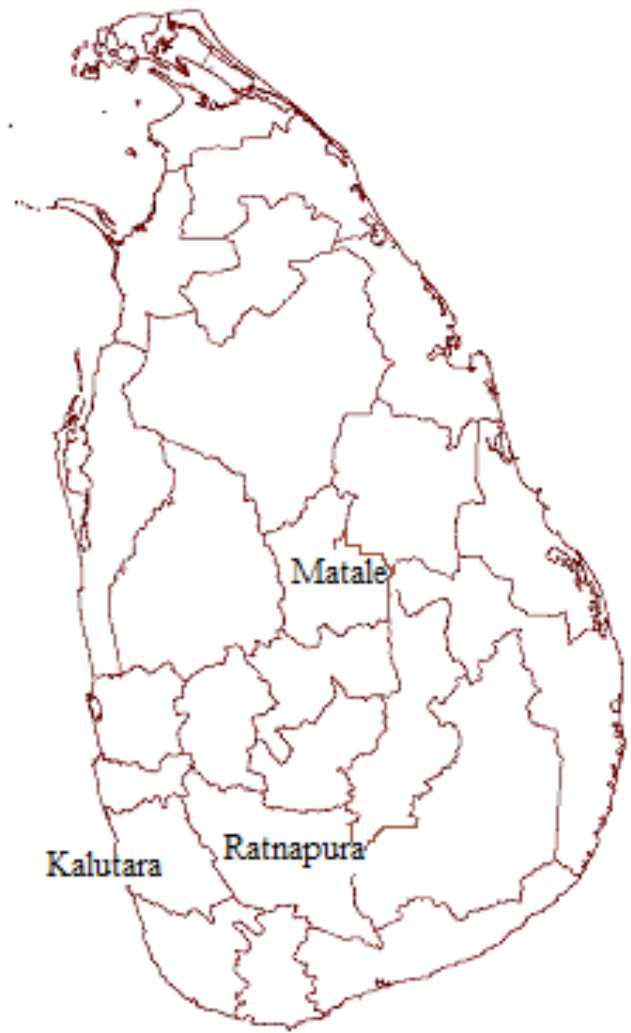


Table 2.1: $\quad$ Details of selected plantations

\begin{tabular}{|c|c|c|}
\hline District & Name of the Plantation & Age, yr \\
\hline \multirow{7}{*}{ Ratnapura } & Gomaragala (Gg) & 7 \\
\hline & Ihalakanda (Ik) & 8 \\
\hline & Kalugalhena (Kh) & 4 \\
\hline & Munihinkanda (Mk) & 6 \\
\hline & Panthiya $1\left(\mathrm{Pt}_{1}\right)$ & 6 \\
\hline & Panthiya $2\left(\mathrm{Pt}_{2}\right)$ & 6 \\
\hline & St. Anthony's (SA) & 4 \\
\hline \multirow{4}{*}{ Kalutara } & Hartley $(\mathrm{Hl})$ & 3 \\
\hline & Kukuleganga (Kg) & 5 \\
\hline & Leelajan (Lj) & 3 \\
\hline & Pelawatta $(\mathrm{Pw})$ & 4 \\
\hline \multirow{4}{*}{ Matale } & Ambanganga (Ag) & 2 \\
\hline & North Matale (NM) & 3 \\
\hline & Salagama (Sg) & 2 \\
\hline & Seelani (Sl) & 3 \\
\hline
\end{tabular}

\subsection{MODEL CONSTRUCTION}

In the preliminary stage of the analysis, relationship between dbh and age of mahogany monocultures in respect to good, moderate and poor site types was identified graphically. Possible outliers were eliminated at the beginning of the analysis. In order to recognize the magnitude of the two variables and the direction of the relationship between dbh and age of mahogany, correlation coefficient (r) was used prior to formulate the model. A theoretical basic model structure was developed to express the relationship between dbh and age for each site type. Regression analysis was applied within the basic model structure for the purpose of parameter estimation separately for three different site types. Both linear regression and nonlinear regression analysis using MINITAB and GENSTAT statistical software were used for this purpose. Both untransformed and transformed explanatory variables (i.e., square, square root, logarithmic and inverse) were tested for the model with the intention on preparing biologically sound and high performing models.

\subsection{SELECTION OF THE BEST MODELS FOR EACH SITE TYPES}

The best models for dbh and age relationship for good, moderate and poor sites were selected statistically by using coefficient of determination $\left(\mathrm{R}^{2}\right)$ and by residual plot analysis. In order to maintain a consistency, the same structure was used all three site types.

\subsection{CONSTRUCTION OF A COMMON MODEL}

In order to reduce the complexity by using three different parameter sets for same basic structure for good, moderate and poor sites, application of a common model for all site types was statistically tested using pooled data. Application of that common model for all site types was tested with differences of normal residuals using one way ANOVA and Turkey's pair wise comparison. The common model was expected as appropriate for all three site types only if the normal residuals are not significantly different from each other. Otherwise separate models were decided to use.

\subsection{IMPROVEMENT OF THE MODELS THAT WERE SIGNIFICANT}

Previous strategy was not successful to produce reliable common model. Therefore, analysis was further progressed to find out the possibility of using a common set of parameters for the models which were significant for different site types. For this reason, multiple linear regression was used with an additional site index (average height/age) for the pooled data. 
Statistical methods that mentioned in the section of 2.2 and 2.3 were again applied to construct a new set of common models, instead of models that were significant for each site.

\section{RESULTS}

Figure 3.1 illustrates the dbh distribution for all measured plantations. The abbreviations that are used for the graphs are given below.

Ag - Ambanganga, Gg - Gomaragala, Hl - Hartley, Ik - Ihalakanda, Kh - Kalugalhena, Kg Kukuleganga, $\mathrm{Lj}$ - Leelajan, $\mathrm{Mk}$ - Munihinkanda, $\mathrm{NM}$ - North Matale, $\mathrm{Pt}_{\mathrm{I}}$ - Panthiya $\mathrm{I}, \mathrm{Pt}_{\mathrm{II}}-$ Panthiya II, Pw - Pelawatta, SA - St Anthony's, $\mathrm{Sl}_{1}-$ Seelani 1, $\mathrm{Sl}_{3}-$ Seelani 3, Sg - Salagama

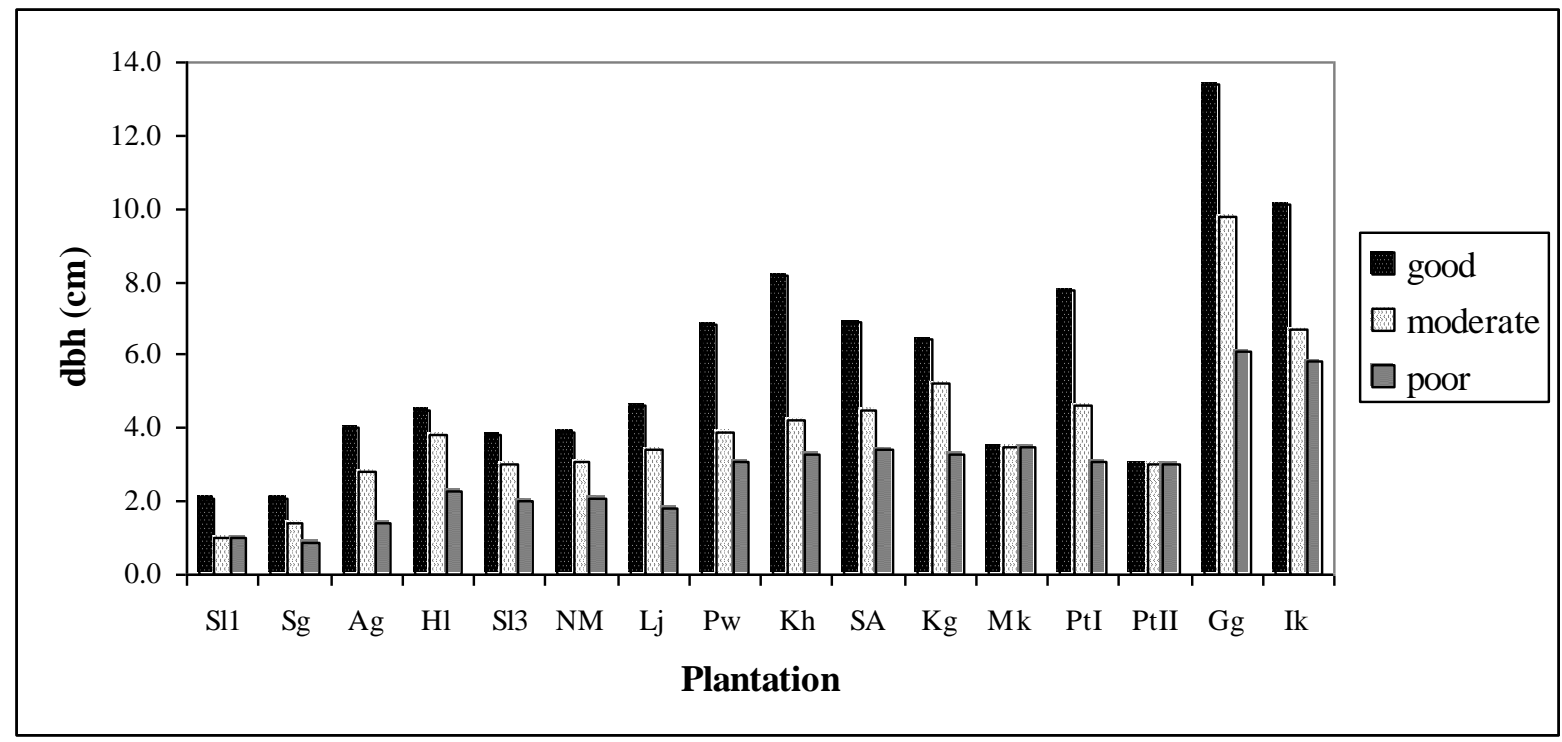

Figure 3.1: $\quad$ dbh distribution of plantations used for this study (Sorted in ascending order on age)

Gomaragala (Gg) plantation which is seven years old has the highest dbh for different growth types. Dbh values, however, in Ihalakanda (Ik) plantation which is eight years were old lower than that of Gomararagala. Mean values for dbh in Kalugalhena (Kh), St Anthony's (SA), Panthiya I $\left(\mathrm{Pt}_{\mathrm{I}}\right)$, Kukuleganga $(\mathrm{Kg})$ and Pelawatta $(\mathrm{Pw})$ plantations range between $6.0 \mathrm{~cm}$ to $8.0 \mathrm{~cm}$. Dbh values in other plantations range between $1.0 \mathrm{~cm}$ to $4.0 \mathrm{~cm}$.

3.1

\section{ELECTED BEST MODELS}

The final outcome of this study was the site specific growth models (for good, moderate and poor site) with three different parameter sets for dbh and age relationship for mahogany monocultures. Dbh showed an exponential relationship with age for the finally selected three site specific models for (good, moderate and poor sites). Equations of 3.1, 3.2, and 3.3 respectively represent growth models for good, moderate and poor sites.

Dbh $=2.443 * 1.207^{\text {age }}$
dbh $=1.736 * 1.184^{\text {age }}$
dbh $=0.919 * 1.267^{\text {age }}$

Where, $\mathrm{dbh}=$ diameter at the breast height, age $=$ age of the mahogany tree

Figure 3.2 illustrates the fitted lines of the models built to predict dbh vs age. The $\mathrm{R}^{2}$ values for good, moderate and poor sites are $78.8 \%, 71.2 \%$, and $81.5 \%$ respectively. 


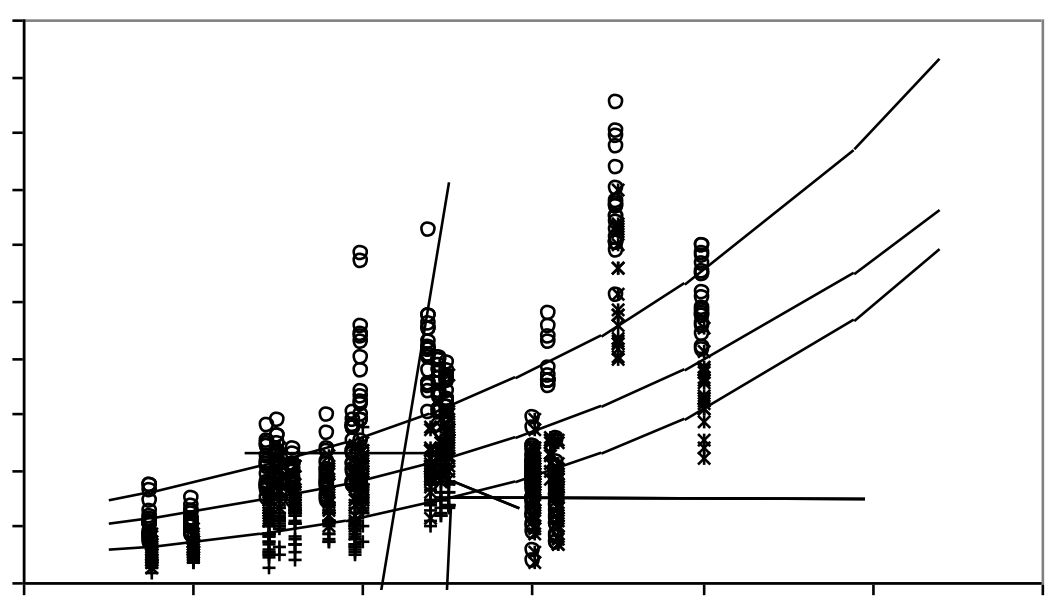

Figure 3.2: $\quad$ Fitted line plot of dbh vs age for three site classes.

The $\mathrm{R}^{2}$ values were above $70 \%$ and the residual distributions were good. Finally, a height based site/growth classification system was also introduced in this study, so that the appropriate model can be used referring the growth quality table (table 3.1).

The attempt made to establish a common model for all three site types was not successful as the normal residuals were significantly different for good, moderate and poor sites. Inclusion of the site representative index was also not successful. Therefore it was decided to use separate models for three site types.

Table 3.1: $\quad$ Growth quality table developed using total height

\begin{tabular}{llll}
\hline Age (year) & Poor growth & Moderate growth & Good growth \\
& & & \\
\hline 2 & $<2.0 \mathrm{~m}$ & $2.1-3.4 \mathrm{~m}$ & $>3.5 \mathrm{~m}$ \\
3 & $<2.5 \mathrm{~m}$ & $2.6-3.9 \mathrm{~m}$ & $>4.0 \mathrm{~m}$ \\
4 & $<4.0 \mathrm{~m}$ & $4.1-5.9 \mathrm{~m}$ & $>6.0 \mathrm{~m}$ \\
5 & $<4.5 \mathrm{~m}$ & $4.6-6.4 \mathrm{~m}$ & $>6.5 \mathrm{~m}$ \\
7 & $<5.0 \mathrm{~m}$ & $5.1-7.9 \mathrm{~m}$ & $>8.0 \mathrm{~m}$ \\
8 & $<5.5 \mathrm{~m}$ & $5.6-8.4 \mathrm{~m}$ & $>8.5 \mathrm{~m}$ \\
\hline
\end{tabular}

\section{CONCLUSION}

Construction of a common model for all site types was not successful. As dbh shows an exponential relationship with the age, that type was selected as the basic structure for the finally selected model.

\section{RECOMMENDATION}

Age range of mahogany monocultures are restricted in to younger plantations due to lack of mature monocultures in Sri Lanka. Therefore this study should be extended with the data collected from mature plantations in the future. 


\section{REFERENCES}

Abdullah, N., Jubok, Z. H. J., Jonney, N. J.B., 2008. Multiple regression models of the volumetric stem biomass, Mathematics with Economics Programme, School of Science \& Technology, Universitiy Malaysia Sabah, Malaysia.

Ariyadasa, K. P., 2002. Assesments of tree resources in the home gardens of Sri Lanka, FAO partnership programme, Sri Lanka.

Evans, J., 1996. Plantation forestry in the tropics, Second edition, pp 51-83.

Herath, H.M.A.B., 2007. Changes of crown parameters with the age and growth of Eucalyptus grandis Hill ex.Meiden, University of Sri Jayewardenepura, Nugegoda, Sri Lanka.

Platino, F., Erguera, C.R., Chavez, J.M., undated, Conservation and use of mahogany in forest ecosystems in Mexico.

Subasinghe, S.M.C.U.P., 2009. Lecture notes on Natural Resource Modelling, Department of Forestry and Environmental Science, University of Sri Jayewardenepura, Sri Lanka.

Subasinghe, S.M.C.U.P., 2009. Personal communication, Senior Lecturer, Department of Forestry and Environmental Science, University of Sri Jayewardenepura, Sri Lanka.

Thornley, J. H. M., 1999. Modelling stem height and diameter growth in plants, Institute of Terrestrial Ecology (edinburgh), United Kingdom.

Vanclay, J. K., 2002. Growth modelling and yield prediction for sustainable forest Management, The Malaysian Forester 66(1):58-69. 